\title{
GluN2B protein deficits in the left, but not the right, hippocampus in schizophrenia
}

\author{
Amy E Geddes ${ }^{1,2,3}$, Xu-Feng Huang ${ }^{1,2,3}$ and Kelly A Newell ${ }^{1,2,3^{*}}$
}

\begin{abstract}
Background: Increasing evidence indicates that alterations to the function and subunit composition of the glutamatergic NMDA receptor are associated with the pathophysiology of schizophrenia. The GluN2B protein is a structural and functional subunit of the NMDA receptor, with a growing body of evidence indicating it plays a critical role in cognitive functions mediated by the NMDA receptor. The hippocampus plays a key role in cognitive function, with studies suggesting lateralised glutamatergic dysfunction in this region may contribute to the cognitive deficits observed in schizophrenia patients. The present study, for the first time, investigated GluN2B protein and binding density in the left and right hippocampus of 20 schizophrenia subjects compared to 20 matched controls.

Methods: The dentate gyrus of 20 schizophrenia and 20 control subjects, matched for age, post-mortem interval, and $\mathrm{pH}$, was obtained from the NSW Tissue Resource Centre, Australia. Each group consisted of dentate gyrus from the left hemisphere $(n=10)$ and right hemisphere $(n=10)$. GluN2B protein density was measured via immunoblotting. GluN2B binding density was measured using the GluN2B antagonist, $\left[{ }^{3} \mathrm{H}\right]$ Ifenprodil. Analyses of covariance, covarying for demographic variables that influenced the data, were used to test for statistical significance between schizophrenia and control groups. Pearson's correlations were used to determine the association of GluN2B protein and binding density with demographic and clinical variables, including lifetime antipsychotic drug exposure.

Results: GluN2B protein levels were decreased by $43 \%$ in the left hemisphere of schizophrenia subjects compared to controls ( $p=0.012$ ). There was no difference in GluN2B protein levels in the right hemisphere of schizophrenia subjects compared to controls. There were no differences in $\left.{ }^{3} \mathrm{H}\right]$ Ifenprodil binding according to diagnosis or hemisphere. There were no associations between GluN2B measures and lifetime antipsychotic drug exposure.

Conclusions: Our findings provide the first evidence of GluN2 protein abnormalities in the hippocampus in schizophrenia, highlighting the hippocampal lateralisation in this disorder. We suggest this deficit could contribute to the cognitive dysfunctions that arise in patients. These findings provide preliminary support for the development of therapeutics that target the GluN2B subunit, as a novel therapy for schizophrenia, especially the cognitive dysfunctions.
\end{abstract}

Keywords: GluN2B, NR2B, NMDA receptor, hippocampus, dentate gyrus, human brain

\section{Background}

The hippocampus plays an important role in learning and memory, cognitive functions that are disrupted in schizophrenia [1]. Several lines of research have shown that there are various structural and functional abnormalities in the hippocampus of schizophrenia patients, including a reduction in hippocampal volume, altered

\footnotetext{
* Correspondence: knewell@uow.edu.au

${ }^{1}$ Faculty of Science, Medicine and Health, University of Wollongong,

Northfields Ave, Wollongong NSW 2522, Australia

${ }^{2}$ Illawarra Health and Medical Research Institute, Wollongong NSW 2522,

Australia

Full list of author information is available at the end of the article
}

synaptic connections (evidenced through reductions in synaptosomal proteins such as synaptophysin, SNAP-25 and synapsin) and changes in neurotransmitter receptors, implicating the hippocampus in the pathophysiology of schizophrenia [2].

Dysregulation of glutamatergic neurotransmission, particularly associated with the N-methyl-D-aspartate glutamate receptor (NMDAR) is also widely believed to play a central role in schizophrenia pathophysiology [3-5]. The NMDAR is assembled in various subunit combinations, with obligatory GluN1 subunits coupled primarily with GluN2A, B, C, or D subunits [6]. Various studies have 
found alterations in NMDAR binding and GluN1 subunit mRNA and protein in the hippocampus of schizophrenia subjects (For review see [3]). Some replicated findings include a decrease in GluN1 mRNA in the dentate gyrus of schizophrenia patients $[7,8]$, a decrease or no change in NMDAR binding density $[7,9,10]$ and most interestingly a more pronounced decrease in NMDAR binding and GluN1 mRNA and protein in the left hippocampus of schizophrenia subjects compared to the right $[8,9,11]$. These studies suggest a lateralised glutamatergic dysregulation in the hippocampus of schizophrenia subjects [2]. With regards to the GluN2 subunits, one study has reported an increase in GluN2B mRNA in the hippocampus in schizophrenia, with two further studies reporting no change, and no changes have been reported for GluN2A mRNA, or the less expressed $2 \mathrm{C}$ and $2 \mathrm{D}$ subunits $[7,10,12]$. The status of GluN2 proteins in the hippocampus in schizophrenia is currently unknown, however one study did report no change in $\left[{ }^{3} \mathrm{H}\right]$ ifenprodil binding to GluN2B in the hippocampus of schizophrenia subjects [10]. These aforementioned studies, however, did not report hemisphere specific analyses which is an important aspect to consider in studies of the hippocampus [2].

The GluN2 subunit composition defines the functional properties of the NMDAR [3], therefore to understand the NMDAR dysregulation in schizophrenia it is critical to investigate alterations to the GluN2 subunits. GluN2A and GluN2B are the principle subunits in the hippocampus [13]; evidence suggests that the GluN2B subunit in the hippocampus is particularly important for NMDAR channel function [14], long-term potentiation (LTP) and associated cognitive functions such as spatial learning [15]. Accordingly, specifically targeting the GluN2B subunit has been suggested as a novel mechanism to treat cognitive dysfunction in schizophrenia patients and other cognitive disorders $[16,17]$.

The aim of this study was to determine whether there are alterations in GluN2B subunit density in the hippocampus of schizophrenia subjects compared to controls and whether any effects were hemisphere specific. We used immunoblot to detect GluN2B protein density and $\left[{ }^{3} \mathrm{H}\right]$ ifenprodil, which binds to the polyamine site of the GluN2B subunit, to assess GluN2B binding density.

\section{Methods}

\section{Brain Tissue}

Post-mortem human brain tissue was acquired from the NSW Tissue Resource Centre at the University of Sydney. The cohorts consisted of schizophrenia patients, with the diagnosis of schizophrenia confirmed according to DSMIV and healthy controls, with no known history of psychiatric illness (Table 1). The cohort for the western blotting consisted of 20 schizophrenia and 20 control subjects; the cohort for receptor binding consisted of 20 schizophrenia and 21 control subjects. There was an overlap of 84\% (37/ 44) between subjects included in the western blot and receptor binding studies. There were no significant differences in age, brain $\mathrm{pH}$, post-mortem interval (PMI) or brain weight between the schizophrenia and control subjects included in the protein or binding studies. This study was approved by the University of Wollongong Human Research Ethics Committee (HE99/222).

\section{Immunoblot}

Immunoblotting was performed as previously described [18]. Tissue from the dentate gyrus of the hippocampus was homogenised in $0.1 \mathrm{M}$ TrisHCl containing $10 \mu \mathrm{l} / \mathrm{ml}$ protease inhibitor cocktail (Sigma-Aldrich), $0.625 \mu \mathrm{l} / \mathrm{ml}$ aprotinin and $0.5 \mu \mathrm{l} / \mathrm{ml}$ glycerol. GluN2B protein density was measured using an anti-GluN2B antibody (\#MAB5778, 1/625; Millipore) diluted in PBS-T containing 1\% skim milk. A mouse anti-actin antibody was used as an internal standard (\#MAB1501, 1/100 000; Millipore). Samples were run in triplicate at a concentration of $10 \mu \mathrm{g}$ of total protein. GluN2B protein bands were detected on Kodak BioMax MR Film (Sigma-Aldrich) using enhanced chemiliuminescence reagents (GE Healthcare). Films were analysed using Quantity One software (BioRad); the optical density of each band was normalised to the respective $\beta$-actin band and averaged over the three runs.

\section{In situ radioligand binding}

$\left[{ }^{3} \mathrm{H}\right]$ Ifenprodil binding was performed based on the method described previously [19]. Three slides per subject, each containing $14 \mu \mathrm{m}$ hippocampal sections, were incubated for 3 hours at $4^{\circ} \mathrm{C}$ in $0.05 \mathrm{M}$ TrisHCl (pH 7.4) with $20 \mathrm{nM}\left[{ }^{3} \mathrm{H}\right]$ Ifenprodil (GluN2B antagonist: specific activity $40 \mathrm{Ci} / \mathrm{mmol}$; PerkinElmer). Due to previous findings that $\left[{ }^{3} \mathrm{H}\right]$ ifenprodil has some affinity for sigma receptors, piperazine acceptor sites, and non-GluN2B polyamine sites [20-22], the following pharmacological inhibitors were included in the incubation assay: $3 \mu \mathrm{M}$ $\mathrm{R}(+)$-3-(3-hydroxyphenyl)-N-propylpiperidine hydrochloride (+3PPP; to block non-specific binding to the sigma receptor), $30 \mu \mathrm{M}$ GBR-12909 (to block piperazine sites) and $1 \mathrm{mM}$ trifluoperazine (to block low affinity polyamine sensitive sites on adrenergic, dopaminergic and cholinergic receptors). Adjacent sections were incubated in the same solution, with the addition of $20 \mu \mathrm{M}$ Ifenprodil (Sigma-Aldrich) to determine any non-specific binding. All sections were washed in $0.05 \mathrm{M}$ TrisHCl ( $\mathrm{pH}$ 7.4) for $3 \times 5$ minutes at $4{ }^{\circ} \mathrm{C}$, rinsed in distilled water and airdried. All slides were exposed to Kodak BioMax MR Film (Sigma-Aldrich) for 16 weeks. Films were analysed using Quantity One software; quantification was performed by taking the average optical density from the dentate gyrus in three slides. Specific binding was determined 
Table 1 Cohort demographic and clinical characteristics

\begin{tabular}{|c|c|c|c|c|c|}
\hline Variable & Cohort & Control & Schizophrenia & $t$ & $p$ \\
\hline \multirow[t]{2}{*}{$n$} & Western Blot & 20 & 20 & & \\
\hline & Receptor binding & 21 & 20 & & \\
\hline Age at death & Western Blot & $54.5 \pm 13.4(24-73)$ & $54.7 \pm 12.8(27-75)$ & -0.036 & 0.971 \\
\hline Mean years $\pm S D$ (range) & Receptor binding & $55.3 \pm 13.1(24-73)$ & $54.8 \pm 12.8(27-75)$ & 0.132 & 0.895 \\
\hline Post-mortem interval & Western Blot & $28.2 \pm 13.3$ & $29.5 \pm 12.5$ & -0.307 & 0.761 \\
\hline Mean hours \pm SD & Receptor binding & $30.5 \pm 13.6$ & $28.9 \pm 12.3$ & 0.388 & 0.700 \\
\hline $\mathrm{pH}$ & Western Blot & $6.47 \pm 0.35$ & $6.47 \pm 0.16$ & 0.069 & 0.945 \\
\hline Mean \pm SD & Receptor binding & $6.44 \pm 0.35$ & $6.47 \pm 0.16$ & -0.381 & 0.706 \\
\hline \multirow[t]{2}{*}{ Gender } & Western Blot & $12 \mathrm{M} / 8 \mathrm{~F}$ & $12 \mathrm{M} / 8 \mathrm{~F}$ & N/A & N/A \\
\hline & Receptor binding & $12 \mathrm{M} / 9 \mathrm{~F}$ & $12 \mathrm{M} / 8 \mathrm{~F}$ & N/A & N/A \\
\hline \multirow[t]{2}{*}{ Hemisphere } & Western Blot & $10 \mathrm{~L} / 10 \mathrm{R}$ & $11 \mathrm{~L} / 9 \mathrm{R}$ & N/A & N/A \\
\hline & Receptor binding & $10 \mathrm{~L} / 11 \mathrm{R}$ & $10 \mathrm{~L} / 10 \mathrm{R}$ & N/A & $\mathrm{N} / \mathrm{A}$ \\
\hline Brain weight & Western Blot & $1410 \pm 128$ & $1358 \pm 172$ & 1.085 & 0.285 \\
\hline Mean grams \pm SD & Receptor binding & $1396 \pm 139$ & $1358 \pm 172$ & 0.792 & 0.433 \\
\hline Estimated daily antipsychotic drug dose & Western Blot & N/A & $782 \pm 543$ & $\mathrm{~N} / \mathrm{A}$ & N/A \\
\hline Mean $C P Z$ equiv $\pm S D$ & Receptor binding & N/A & $809 \pm 529$ & N/A & N/A \\
\hline Age of onset & Western Blot & N/A & $24.1 \pm 8.2(14-44)$ & N/A & N/A \\
\hline Mean years $\pm S D$ (range) & Receptor binding & N/A & $23.6 \pm 8.1(14-44)$ & N/A & N/A \\
\hline Duration of illness & Western Blot & N/A & $30.6 \pm 11.9(12-47)$ & N/A & N/A \\
\hline Mean years $\pm S D$ (range) & Receptor binding & N/A & $30.7 \pm 11.9(12-47)$ & N/A & N/A \\
\hline
\end{tabular}

There was an overlap of $84 \%$ (37/44) between subjects included in the western blot and receptor binding studies. Independent t-tests show no significant differences in age at death, post-mortem interval, $\mathrm{pH}$ or brain weight between schizophrenia and control groups; Abbreviations: $M$, male; $F$, female; $L$, left; $R$, right; PMI, post-mortem interval; CPZ equiv, chlorpromazine equivalents. N/A, not applicable.

by subtracting non-specific binding density from total binding density.

\section{Statistical Analyses}

The data were checked for triplicate (standard deviation > $30 \%$ mean) and population outliers (using box-plots) and Kolmogorov-Smirnov tests were used to confirm data normality. T-tests, ANOVAs and ANCOVAs with LSD posthoc were used to determine the effects of diagnosis overall and within the left and right hemispheres, co-varying for variables that were shown to correlate with the data. Pearson's correlations were used to determine relationships to continuous variables including age at death, PMI, pH, brain weight, antipsychotic medication, age of illness onset, and duration of illness.

\section{Results}

Left hippocampal deficits in GluN2B subunit protein in schizophrenia subjects

While we observed no overall difference in GluN2B protein density in the dentate gyrus of schizophrenia subjects compared to controls $\left(t_{36}=1.452, \mathrm{p}=0.155\right)$, we found a significant difference between hemisphere-specific subgroups $\left(\mathrm{F}_{3,34}=2.882, \mathrm{p}=0.050\right)$, with a $43 \%$ reduction in GluN2B protein in the left hippocampus of schizophrenia subjects compared to the left hippocampus of controls $(\mathrm{p}=0.012)$ and a $40 \%$ reduction in GluN2B protein in the left hippocampus of schizophrenia subjects compared to the right hippocampus from schizophrenia subjects $(\mathrm{p}=0.023)$ (Figure 1a and $1 \mathrm{~b})$. GluN2B protein density correlated significantly with brain $\mathrm{pH}(\mathrm{r}=-0.386, \mathrm{p}=0.017)$ and there was a trend for a correlation with PMI $(r=-0.318, p=0.051)$ in the whole cohort (Table 2). Similar correlations were observed in the control subjects $(\mathrm{pH}$ : $\mathrm{r}=-0.662, \mathrm{p}=0.002 ;$ PMI: $\mathrm{r}=-0.483, \mathrm{p}=0.036)$ but not the schizophrenia subjects $(\mathrm{pH}: \mathrm{r}=0.162, \mathrm{p}=0.506$; PMI: $\mathrm{r}=-0.116, \mathrm{p}=0.636$ ). ANCOVAs correcting for brain $\mathrm{pH}$ and PMI confirmed that there was no overall difference in GluN2B protein density between schizophrenia and control subjects $\left(\mathrm{F}_{1,34}=2.004, \mathrm{p}=0.166\right)$ and that there was a significant effect between the 4 hemisphere-specific subgroups $\left(\mathrm{F}_{3,32}=3.824, \mathrm{p}=0.019\right)$. Importantly, there was no correlation between GluN2B protein density in the schizophrenia subjects and length of illness, age of disease onset or estimated daily antipsychotic medication dose (Table 2).

\section{No change in GluN2B binding density in schizophrenia subjects compared to controls}

There was no overall difference in $\left[{ }^{3} \mathrm{H}\right]$ Ifenprodil binding in the dentate gyrus between schizophrenia and 


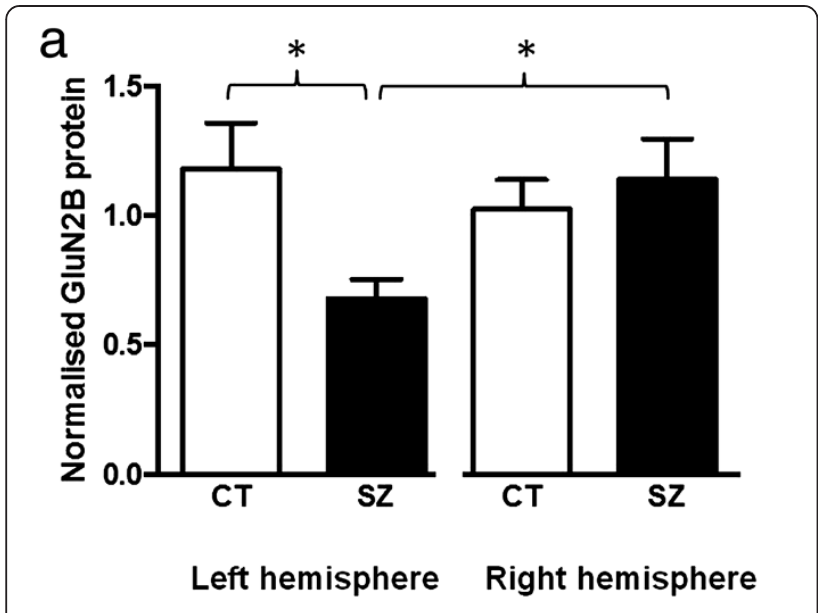

b

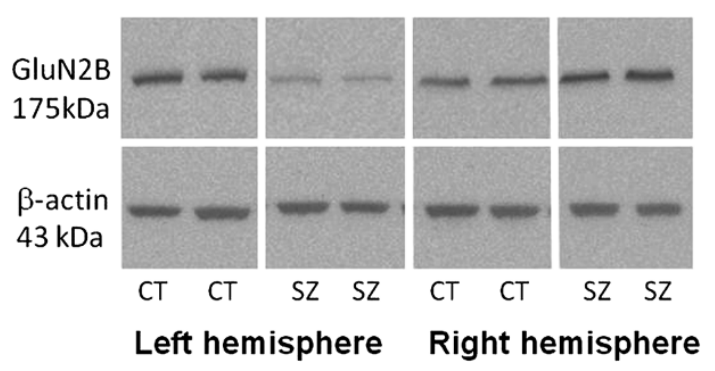

C

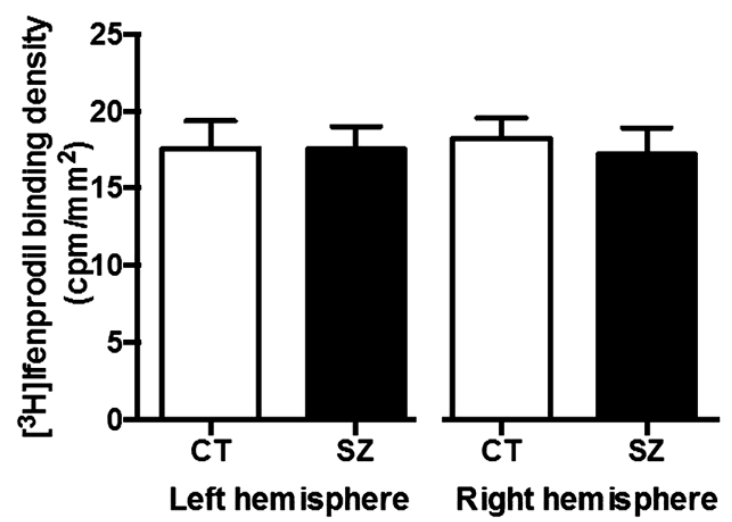

Figure 1 GluN2B protein and binding density in the hippocampus (dentate gyrus) of schizophrenia and control subjects. a. GluN2B protein density, normalised to $\beta$-actin, in the left and right hemisphere of schizophrenia (SZ) and control (CT) subjects. GluN2B was reduced in the left hemisphere of subjects with schizophrenia, compared to the left hemisphere of controls $(-43 \%$, $p=0.012)$ and compared to the right hemisphere of schizophrenia subjects $(-40 \%, p=0.023)$. *:p $<0.05$. b. Representative blot showing GluN2B and $\beta$-actin protein expression in control $(C T)$ and schizophrenia subjects (SZ) from the left and right hemisphere. GluN2B was identified as a single band at the expected molecular weight (175 kDa). c. $\left[{ }^{3} \mathrm{H}\right]$ Ifenprodil binding to GluN2B revealed no significant differences between schizophrenia (SZ) and control (CT) subjects, in the left or right hemisphere. Bars represent mean + SEM. control subjects $\left(t_{39}=0.808, p=0.424\right)$ and no hemisphere dependent effects $\left(\mathrm{F}_{3,37}=0.394, \mathrm{p}=0.758\right)$ (Figure 1c). $\left[{ }^{3} \mathrm{H}\right]$ Ifenprodil binding density correlated with age at death in the whole cohort $(\mathrm{r}=-0.309, \mathrm{p}=0.049)$, showed a trend towards a correlation in control subjects $(\mathrm{r}=-0.408$, $\mathrm{p}=0.067$ ), but did not correlate in schizophrenia subjects $(\mathrm{r}=-0.212, \mathrm{p}=0.369)$ (Table 2). ANCOVAs to correct for age at death confirmed no difference in $\left[{ }^{3} \mathrm{H}\right]$ Ifenprodil binding density between schizophrenia and control subjects $\left(F_{1,38}=0.780, p=0.383\right)$ or hemisphere-specific subgroups $\left(\mathrm{F}_{3,36}=0.472, \mathrm{p}=0.704\right)$. There was no correlation between GluN2B binding density in the schizophrenia subjects and length of illness, age of disease onset or estimated daily antipsychotic medication dose (Table 2).

\section{Discussion}

In the present study we have identified a large (43\%) reduction in GluN2B protein levels in the hippocampal dentate gyrus in schizophrenia. This reduction was specific to the left hemisphere, highlighting the hippocampal lateralisation in the pathophysiology of schizophrenia. In addition, we have confirmed previous results, this time in a larger cohort $(\mathrm{n}=15 \mathrm{cf} . \mathrm{n}=20)$, indicating no change in $\left[{ }^{3} \mathrm{H}\right]$ ifenprodil binding to GluN2B in the hippocampus of schizophrenia subjects in comparison to controls [10] and extended these findings to report no hemisphere specific alteration in GluN2B binding density.

It is well documented that the hippocampus is altered in schizophrenia and there is evidence to suggest that the left hemisphere shows more pronounced deficits in NMDAR expression than the right hemisphere. Previous studies have reported a more pronounced decrease in GluN1 mRNA and protein in the left hemisphere of schizophrenia subjects $[8,11]$ as well as a reduction in $\left[{ }^{123} \mathrm{I}\right]$ CNS-1261 binding to the NMDAR channel in the left hippocampus of medication free schizophrenia subjects [9]. Ours is the first study in the hippocampus to report such a lateralisation effect with any of the GluN2 subunits, however, to our knowledge, the protein density of the other GluN2 subunits has not yet been investigated in this region. It has previously been reported that deletion of the GluN1 subunit in the CA1 region of the hippocampus results in reduced expression of the GluN2B subunit in the dendrites of pyramidal neurons in mice [23], suggesting our finding of reduced GluN2B in the hippocampus could be associated with the reductions in GluN1 previously reported in the left hippocampus in schizophrenia.

While we found a reduction in GluN2B protein levels in the present study, this was accompanied by no change in GluN2B binding density. $\left[{ }^{3} \mathrm{H}\right]$ Ifenprodil binds to the polyamine site on GluN2B subunits. While ifenprodil does also have some affinity for sigma, piperazine, adrenergic receptors and other polyamine sites [20-22], pharmacological inhibitors were used to block these sites in the 
Table 2 Pearsons correlations for continuous variables influencing GluN2B binding and protein expression in the hippocampus of all subjects, control subjects only and schizophrenia subjects only

\begin{tabular}{|c|c|c|c|c|c|c|c|}
\hline \multirow[t]{3}{*}{ Variable } & & \multicolumn{2}{|c|}{ All subjects } & \multicolumn{2}{|l|}{ Control } & \multicolumn{2}{|c|}{ Schizophrenia } \\
\hline & & GluN2B & GluN2B & GluN2B & GluN2B & GluN2B & GluN2B \\
\hline & & Protein & Binding & Protein & Binding & Protein & Binding \\
\hline$n$ & & 38 & 41 & 19 & 21 & 19 & 20 \\
\hline \multirow[t]{2}{*}{ Age at death } & r & 0.16 & -0.309 & 0.207 & -0.408 & 0.152 & -0.212 \\
\hline & $\mathrm{p}$ & 0.338 & 0.049 & 0.395 & 0.067 & 0.534 & 0.369 \\
\hline \multirow[t]{2}{*}{ Post-mortem interval } & r & -0.318 & 0.054 & -0.483 & 0.061 & -0.116 & 0.030 \\
\hline & $p$ & 0.051 & 0.738 & 0.036 & 0.794 & 0.636 & 0.901 \\
\hline \multirow[t]{2}{*}{$\mathrm{pH}$} & r & -0.386 & 0.068 & -0.662 & 0.226 & 0.162 & -0.255 \\
\hline & $p$ & 0.017 & 0.671 & 0.002 & 0.324 & 0.506 & 0.278 \\
\hline \multirow[t]{2}{*}{ Brain weight } & r & 0.067 & -0.029 & 0.028 & 0.152 & 0.023 & -0.218 \\
\hline & $\mathrm{p}$ & 0.688 & 0.855 & 0.908 & 0.512 & 0.926 & 0.356 \\
\hline \multirow[t]{2}{*}{ Duration of illness } & r & N/A & N/A & N/A & N/A & -0.056 & -0.192 \\
\hline & $\mathrm{p}$ & N/A & N/A & N/A & N/A & 0.819 & 0.430 \\
\hline \multirow[t]{2}{*}{ Age of onset } & r & N/A & N/A & N/A & N/A & 0.313 & 0.007 \\
\hline & $\mathrm{p}$ & N/A & N/A & N/A & N/A & 0.193 & 0.977 \\
\hline \multirow[t]{2}{*}{ Estimated daily antipsychotic drug dose } & r & N/A & N/A & N/A & N/A & -0.156 & -0.368 \\
\hline & $\mathrm{p}$ & N/A & $\mathrm{N} / \mathrm{A}$ & $\mathrm{N} / \mathrm{A}$ & N/A & 0.525 & 0.111 \\
\hline
\end{tabular}

Significant and borderline significant correlations are highlighted in bold. N/A, not applicable.

binding assay. Therefore, it is unlikely that the discrepancy between binding and protein is a result of $\left[{ }^{3} \mathrm{H}\right]$ Ifenprodil binding to non-GluN2B sites. It is possible however that that these two techniques label different populations of GluN2B subunits. Under the conditions used in the present study (i.e. the use of tissue sections rather than cell lysed homogenates), $\left[{ }^{3} \mathrm{H}\right]$ ifenprodil would bind primarily to cell surface receptors, while the immunoblot would detect GluN2B protein in all cellular compartments. This suggests that the reduction observed in GluN2B protein in the present study might represent a reduction in intracellular protein levels. The implications of such localised reductions remain unclear [24]. Similar to our study, in cortical brain areas it has been shown that despite no change in $\left[{ }^{3} \mathrm{H}\right]$ ifenprodil binding [25], there was a reduction in GluN2B protein in schizophrenia compared to control subjects, which was specific to the endoplasmic reticulum [26], suggesting there may be altered production, degradation or trafficking of GluN2B protein in schizophrenia. While we did not examine GluN2B mRNA in the present study, two previous studies reported no change in GluN2B mRNA levels in the dentate gyrus in schizophrenia $[10,12]$, therefore it is unlikely the findings in the present study represent changes in GluN2B production. It is possible however that our findings reflect disturbances to GluN2B trafficking, degradation, or other aspects of GluN2B regulation. Further studies, specifically examining isolated cellular compartments and proteins that regulate trafficking/ degradation of GluN2B, as well as assessments of GluN2B phosphorylation and activation would be important to further understand the GluN2B alterations in the hippocampus in schizophrenia.

GluN2B containing NMDARs play a critical role in cognitive functions, especially in the hippocampus (For review see [27]). Selective reduction of GluN2B-containing NMDARs in the hippocampus has been reported to produce cognitive deficits in rodents $[15,28]$ as well as disrupting underlying molecular processes such as LTP [15]. Specifically, the left hippocampus has previously been associated with verbal and visual memory performance in schizophrenia subjects [29]. Therefore, a reduction in NMDARs or altered composition of the NMDAR subunits in hippocampal subregions, such as that found in the present study, may be a contributing factor to the cognitive deficits observed in these patients. Therapies aiming to enhance GluN2B function or activity have been shown to improve cognitive function in animal models of ageing-induced cognitive impairment [30]. Similarly, over-expression of GluN2B in transgenic mice results in increased cognitive ability [31]. Along these lines, positive allosteric modulation, selective for GluN2B-containing NMDARs has been proposed as a novel therapeutic strategy for the treatment of schizophrenia and cognitive dysfunction more generally $[16,17]$. Our finding therefore of reduced GluN2B protein in the hippocampus, is likely to contribute to the cognitive symptoms in schizophrenia patients, and supports the idea that GluN2B positive 
allosteric modulators could potentially be therapeutic for cognitive dysfunctions in schizophrenia.

As with all post-mortem human brain studies of this nature, we cannot rule out an influence of ante-mortem medication on our data. However, we observed no correlation between antipsychotic dose (measured as chlorpromazine equivalents) and GluN2B binding or protein levels. Furthermore, there is evidence from animal studies that antipsychotic drug treatment does not alter GluN2B protein levels in the brain [32-34], suggesting that our findings are unlikely to be due to the effects of pre-mortem antipsychotic drug treatment.

\section{Conclusion}

In conclusion, the present study for the first time revealed that GluN2B protein levels are significantly decreased specifically in the left hippocampus (dentate gyrus) of schizophrenia subjects compared to controls. We suggest this reduction may be associated with cognitive symptoms arising in schizophrenia subjects. While further studies are warranted to determine the functional implications of this reduction and if this reduction is common to other GluN2 subunits or hippocampal subregions, our findings provide preliminary support for the development of GluN2B selective positive modulators as a novel therapy for schizophrenia, especially the cognitive dysfunctions.

\section{Abbreviations \\ LTP: long-term potentiation; NMDAR: N-methyl-D-aspartate receptor; PMl: post-mortem interval.}

\section{Competing interests}

All authors declare that they have no competing interests.

\section{Authors' contributions}

All authors contributed to the study design. AED performed the western blot and receptor binding experiments and wrote the first draft of the manuscript. All authors have contributed to and approved the final manuscript.

\section{Authors' information}

AED is a doctoral student in the School of Medicine, University of Wollongong. XFH is a Senior Professor in the School of Medicine, University of Wollongong and Deputy Executive Director (Science) at the Illawarra Health and Medical Research Institute. KAN is a Senior Lecturer in the School of Medicine, University of Wollongong. All authors are also affiliated scientists with the Illawarra Health and Medical Research Institute and the Schizophrenia Research Institute.

\section{Acknowledgements}

This work was supported by the Schizophrenia Research Institute, utilising infrastructure funding from the NSW Ministry of Health. Post-mortem brain tissues were received from the NSW Tissue Resource Centre, which is supported by the National Health and Medical Research Council of Australia, Schizophrenia Research Institute and the National Institute of Alcohol Abuse and Alcoholism (NIH (NIAA) R24AA012725). Amy Geddes was supported by an lan Scott Postgraduate Scholarship from Australian Rotary Health.

\section{Author details}

${ }^{1}$ Faculty of Science, Medicine and Health, University of Wollongong, Northfields Ave, Wollongong NSW 2522, Australia. ${ }^{2}$ Illawarra Health and Medical Research Institute, Wollongong NSW 2522, Australia. ${ }^{3}$ Schizophrenia Research Institute, Darlinghurst NSW 2010, Australia.
Received: 27 May 2014 Accepted: 17 September 2014

Published online: 08 October 2014

\section{References}

1. Sweatt JD: Hippocampal function in cognition. Psychopharmacol (Berl) 2004, 174:99-110.

2. Harrison PJ: The hippocampus in schizophrenia: a review of the neuropathological evidence and its pathophysiological implications. Psychopharmacol (Berl) 2004, 174:151-162.

3. Geddes $A E$, Huang XF, Newell KA: Reciprocal signalling between NR2 subunits of the NMDA receptor and Neuregulin1 and their role in schizophrenia. Prog Neuropsychopharmacol Biol Psychiatry 2011, 4:896-904.

4. Kantrowitz JT, Javitt DC: N-methyl-d-aspartate (NMDA) receptor dysfunction or dysregulation: The final common pathway on the road to schizophrenia? Brain Res Bull 2010, 83:108-121.

5. Weickert CS, Fung SJ, Catts VS, Schofield PR, Allen KM, Moore LT, Newell KA, Pellen D, Huang X-F, Catts SV, Weickert TW: Molecular evidence of $\mathrm{N}$-methyl-D-aspartate receptor hypofunction in schizophrenia. $\mathrm{Mol}$ Psychiatry 2012, 18:1185-1192.

6. Paoletti P: Molecular basis of NMDA receptor functional diversity. Eur J Neurosci 2011, 33:1351-1365.

7. Gao XM, Sakai K, Roberts RC, Conley RR, Dean B, Tamminga CA: Ionotropic glutamate receptors and expression of $\mathrm{N}$-methyl-D-aspartate receptor subunits in subregions of human hippocampus: effects of schizophrenia. Am J Psychiatry 2000, 157:1141-1149.

8. Law AJ, Deakin JF: Asymmetrical reductions of hippocampal NMDAR1 glutamate receptor mRNA in the psychoses. Neuroreport 2001, 12:2971-2974.

9. Pilowsky LS, Bressan RA, Stone JM, Erlandsson K, Mulligan RS, Krystal JH, Ell $P J$ : First in vivo evidence of an NMDA receptor deficit in medication-free schizophrenic patients. Mol Psychiatry 2006, 11:118-119.

10. Beneyto M, Kristiansen LV, Oni-Orisan A, McCullumsmith RE, MeadorWoodruff $\mathrm{JH}$ : Abnormal glutamate receptor expression in the medial temporal lobe in schizophrenia and mood disorders. Neuropsychopharmacology 2007, 32:1888-1902.

11. Vrajová M, Štastný F, Horáček J, Lochman J, Šerý O, Peková S, Klaschka J, Höschl C: Expression of the Hippocampal NMDA Receptor GluN1 Subunit and Its Splicing Isoforms in Schizophrenia: Postmortem Study. Neurochem Res 2010, 35:994-1002.

12. McCullumsmith RE, Kristiansen LV, Beneyto M, Scarr E, Dean B, MeadorWoodruff JH: Decreased NR1, NR2A, and SAP102 transcript expression in the hippocampus in bipolar disorder. Brain Res 2007, 1127:108-118.

13. Law AJ, Weickert CS, Webster MJ, Herman MM, Kleinman JE, Harrison PJ: Expression of NMDA receptor NR1, NR2A and NR2B subunit mRNAs during development of the human hippocampal formation. Eur $J$ Neurosci 2003, 18:1197-1205.

14. Akashi K, Kakizaki T, Kamiya H, Fukaya M, Yamasaki M, Abe M, Natsume R, Watanabe M, Sakimura K: NMDA receptor GluN2B (GluR epsilon 2/NR2B) subunit is crucial for channel function, postsynaptic macromolecular organization, and actin cytoskeleton at hippocampal CA3 synapses. J Neurosci Off J Soc Neurosci 2009, 29:10869-10882.

15. Clayton DA, Mesches MH, Alvarez E, Bickford PC, Browning MD: A hippocampal NR2B deficit can mimic age-related changes in long-term potentiation and spatial learning in the Fischer 344 rat. J Neurosci Off J Soc Neurosci 2002, 22:3628-3637.

16. Mony L, Kew JN, Gunthorpe MJ, Paoletti P: Allosteric modulators of NR2B-containing NMDA receptors: molecular mechanisms and therapeutic potential. Br J Pharmacol 2009, 157:1301-1317.

17. Menniti FS, Lindsley CW, Conn PJ, Pandit J, Zagouras P, Volkmann RA: Allosteric modulators for the treatment of schizophrenia: targeting glutamatergic networks. Curr Top Med Chem 2013, 13:26-54.

18. Matosin N, Frank E, Deng C, Huang X-F, Newell KA: Metabotropic glutamate receptor 5 binding and protein expression in schizophrenia and following antipsychotic drug treatment. Schizophr Res 2013, 146:170-176.

19. Ibrahim HM, Hogg AJ Jr, Healy DJ, Haroutunian V, Davis KL, MeadorWoodruff $\mathrm{JH}$ : lonotropic glutamate receptor binding and subunit mRNA expression in thalamic nuclei in schizophrenia. Am J Psychiatry 2000, 157:1811.

20. Hashimoto K, Mantione CR, Spada MR, Neumeyer JL, London ED: Further characterization of $[3 \mathrm{H}]$ ifenprodil binding in rat brain. Eur J Pharmacol Mol Pharmacol 1994, 266:67-77. 
21. Hashimoto K, London ED: Further characterization of [3H] ifenprodil binding to $\sigma$ receptors in rat brain. Eur J Pharmacol 1993, 236:159-163.

22. Basham ME, Sohrabji F, Singh TD, Nordeen EJ, Nordeen KW: Developmental regulation of NMDA receptor $2 B$ subunit $\mathrm{mRNA}$ and ifenprodil binding in the zebra finch anterior forebrain. J Neurobiol 1999, 39:155-167.

23. Fukaya M, Kato A, Lovett C, Tonegawa S, Watanabe M: Retention of NMDA receptor NR2 subunits in the lumen of endoplasmic reticulum in targeted NR1 knockout mice. Proc Natl Acad Sci 2003, 100:4855-4860.

24. McCullumsmith RE, Hammond JH, Shan D, Meador-Woodruff JH: Postmortem Brain: An Underutilized Substrate for Studying Severe Mental IIIness. Neuropsychopharmacology 2014, 39:65-87.

25. Beneyto M, Meador-Woodruff JH: Lamina-specific abnormalities of NMDA receptor-associated postsynaptic protein transcripts in the prefrontal cortex in schizophrenia and bipolar disorder. Neuropsychopharmacol Off Publ Am Coll Neuropsychopharmacol 2008, 33:2175-2186.

26. Kristiansen LV, Patel SA, Haroutunian V, Meador-Woodruff JH: Expression of the NR2B-NMDA receptor subunit and its Tbr-1/CINAP regulatory proteins in postmortem brain suggest altered receptor processing in schizophrenia. Synap N Y N 2010, 64:495-502.

27. Nakazawa K, McHugh TJ, Wilson MA, Tonegawa S: NMDA receptors, place cells and hippocampal spatial memory. Nat Rev Neurosci 2004, 5:361-372.

28. Brigman JL, Wright T, Talani G, Prasad-Mulcare S, Jinde S, Seabold GK, Mathur P, Davis MI, Bock R, Gustin RM, Colbran RJ, Alvarez VA, Nakazawa K, Delpire E, Lovinger DM, Holmes A: Loss of GluN2B-containing NMDA receptors in CA1 hippocampus and cortex impairs long-term depression, reduces dendritic spine density, and disrupts learning. I Neurosci Off J SOC Neurosci 2010, 30:4590-4600.

29. Seidman LJ, Faraone SV, Goldstein JM, Kremen WS, Horton NJ, Makris N, Toomey R, Kennedy D, Caviness VS, Tsuang MT: Left hippocampal volume as a vulnerability indicator for schizophrenia: a magnetic resonance imaging morphometric study of nonpsychotic first-degree relatives. Arch Gen Psychiatry 2002, 59:839-849.

30. Brim BL, Haskell R, Awedikian R, Ellinwood NM, Jin L, Kumar A, Foster TC, Magnusson KR: Memory in aged mice is rescued by enhanced expression of the GluN2B subunit of the NMDA receptor. Behav Brain Res 2013, 238:211-226.

31. Tang YP, Shimizu E, Dube GR, Rampon C, Kerchner GA, Zhuo M, Liu G, Tsien JZ: Genetic enhancement of learning and memory in mice. Nature 1999, 401:63-69.

32. Fumagalli F, Frasca A, Racagni G, Riva MA: Dynamic regulation of glutamatergic postsynaptic activity in rat prefrontal cortex by repeated administration of antipsychotic drugs. Mol Pharmacol 2008, 73:1484-1490.

33. O'Connor JA, Hasenkamp W, Horman BM, Muly EC, Hemby SE: Region specific regulation of NR1 in rhesus monkeys following chronic antipsychotic drug administration. Biol Psychiatry 2006, 60:659-662.

34. Schmitt A, Zink M, Müller B, May B, Herb A, Jatzko A, Braus DF, Henn FA: Effects of long-term antipsychotic treatment on NMDA receptor binding and gene expression of subunits. Neurochem Res 2003, 28:235-241.

doi:10.1186/s12888-014-0274-z

Cite this article as: Geddes et al:: GluN2B protein deficits in the left, but not the right, hippocampus in schizophrenia. BMC Psychiatry 2014 14:274.

\section{Submit your next manuscript to BioMed Central and take full advantage of:}

- Convenient online submission

- Thorough peer review

- No space constraints or color figure charges

- Immediate publication on acceptance

- Inclusion in PubMed, CAS, Scopus and Google Scholar

- Research which is freely available for redistribution 